\title{
Investigating Mediations in Student Activities in an English Immersion Context in Mainland China
}

\author{
Xiaohua Liang \\ Faculty of Education, the University of Hong Kong \\ Room 101, HOC Building, Faculty of Education \\ The University of Hong Kong \\ E-mail: liangxh@hkusua.hku.hk
}

\begin{abstract}
This study aims to investigate the role of mediation in the learning process from a sociocultural perspective, activity theory in particular. This study was carried out in a primary English immersion school within the CCUEI Programs in Mainland China. Data were collected mainly through observations and interviews, which were then supplemented by field notes. Techniques of discourse analysis were used to analyze the data. The recorded peer talk presents an emic picture of what occurred during children's interactions. Research findings show that mediation includes task, teacher talk, peer talk, subject content, semiotic artifacts and other semiotic tools. Peer talk as well as linguistic resources constitutes an important resource aside from teacher talk, where the subject content serves as an important mediational tool in the activity and the content-based immersion programs, while offering students opportunities of using the language in meaningful interactions. The results offer insights to both students and teachers about language learning and about pedagogy and professional education respectively.
\end{abstract}

Keywords: Immersion, Interaction, Mediation, Peer talk

\section{Introduction}

Mediation has long been of interest to researchers. Vygotsky (1978) took human action as the unit of analysis, and stated that the human mind is mediated. He identified two mediational tools that people employ in the development of higher cognition: physical tools and symbolic tools among which language plays a major role. My study aims to investigate whether there are other mediational tools students employ in their learning activities to develop their English spoken language proficiency in Mainland China.

In Mainland China English language teaching has experienced great changes. Recently a new English language curriculum has stipulated English as a compulsory subject starting from at least grade three in primary schools. Primary school English teachers face many challenges including limited English language proficiency (Yu, 2001; Zou, 1998), a lack of systematic in-service training, and few active researchers at this level (Cortazzi \& Jin, 2001; Hu, 2002a, 2002b). The China-Canada-United States Collaborative English Immersion (CCUEI) Program, the first and the most influential immersion program in Mainland China, serves the purpose of improving English language teaching at the preschool and primary levels. The typical characteristic of English immersion programs is the teaching of the English language, subject content, and culture through the medium of English without the use of the students' first language (Francis \& Reyhner, 2002; Reyhner, 1998). The aim of this project was to increase children's confidence in English language learning, to enhance their English language proficiency, to ensure the development of the students' content-based learning to a satisfactory level and to better the students' understanding of Western culture while fully developing the students' L1 (Chinese) and maintaining their knowledge of Chinese culture and identity (Qiang, 2000; Qiang \& Zhao, 2000).

Many studies have been carried out on CCUEI (Fang, Wang, \& Siegel, 2001; Pei, 1998; Qiang, 2000; Qiang \& Zhao, 2001; Zhang \& Pei, 2005; Zhao \& Qiang, 2002), and nearly all of them focus on the outcome-oriented effectiveness of immersion. But there are very few research reports on what is occurring in the language learning process, and how the learners appropriate the English language. This research aims to address the following questions:

1) What are the mediations students employ in peer learning processes?

2) How do the mediations function in peer learning?

\section{Mediation and Activity}

According to Lantolf and Thorne (2006), mediation refers to "the process through which humans deploy culturally constructed artifacts, concepts, and activities to regulate (i.e. gain voluntary control over and transform) the material world or their own and each other's social and mental activities" (p. 79). This means that the human mind is mediated through social interactions by semiotic tools, especially language, and mediation is the setting up of connection of the 
self to the outside world (Vygotsky, 1978). Human beings use symbolic tools (not only physical tools) to mediate and regulate their relationship with others and themselves, and change the nature of these relationships. Mediation results in children's internalization of language, knowledge and culture, which is "the reconstruction on the inner, psychological plane of the socially mediated external forms of goal-directed activity" and "anchored in the social activity" (Lantolf, 2000, p.13).

Tasks and activities have long been the interest of researchers engaged in second language teaching and learning. Tasks and activities serve as means to elicit language use from learners which are employed by both teachers and researchers (Ellis, 2003). According to sociocultural theories, activities are collective and social in nature (Vygotsky, 1978; Leont'ev, 1981; Engestrom, 1987, Tsui and Law, 2007), and activities are not only cognition-based, but also include cognitive, executive, evaluative, and emotional aspects (Bedny \& Meister, 1997). From a sociocultural perspective, activity is not a single action but a unit of actions embedded in the activity system that are collective and social in nature (Vogotsky, 1978; Leont'ev, 1981; Luria, 1974), which is addressed by the activity theory and illustrated by the complex model of activity (Engestrom, 1987,1999). Activity Theory has been further developed by Engestrom (1987) who proposes three more components of an activity system: the community, rules and the division of labor (see Figure 1. the complex activity system).

\section{(Figure 1: The complex activity system is here)}

\section{Research Methodology}

This research involved one English immersion primary school which was within the CCUEI Programs in Guangdong Province, where English immersion has been adopted since the establishment of the school in 2004. In September 2004, the school began to recruit students, and the English immersion program was introduced to the 5 classes of Grade 1. At present, the school has 21 English immersion classes with about 800 immersion students. Nearly all the classes in Grade 1, 2, 3, 4 and 5 are immersion classes. The time spent on immersion instruction occupies 20 percent of all the instructions given to the students. English is taught through social science, living science and English language arts.

\subsection{Participants}

The selection of the classes, the teachers and the students for this research was undertaken based on the following criteria:

- the teachers were willing to participate in the research;

- the classrooms were recommended by the principal with the consideration of warm and positive classroom atmosphere; and

- the students were selected based on a wide range of language ability such as higher, intermediate and lower proficiency levels in English.

This represented a large variation among the sample students. Class 4 of Grade 4 in this school was one among the first classes to start the immersion program in September 2004. Six students from this class were chosen as research participants. Most of these students were around 10 years old. The selection criteria aimed to ensure that gender balance and a range of language proficiency were represented. Selection interviews of the candidates recommended by the teacher were conducted in English to ensure that students of high, intermediate and lower proficiency levels were represented.

\subsection{Data collection}

The data of this case study came mainly from classroom observations and interviews. In the classroom observations, audio/video recordings and field notes were used to keep a record of in-class lessons, the students' after-class activities, and the teacher's behavior. Physical artifacts were also collected as a supplementary means. Digital recorders were attached to these 6 students in the class. These recordings were transcribed by the researcher. These methods of data collection offer the opportunity to obtain rich and naturally occurring thick data, which can grant an emic picture of this study.

\subsection{Data analysis}

Engestrom's (1999) framework of activity system formed the basis of the data analysis. The students in the class governed by class rules together with the teacher's instruction, guidance and assistance adopted various mediations in order to improve their language proficiency in their learning activities. For the analysis, techniques of spoken discourse analysis were used to analyze the transcriptions of the data. Mediations emerging from the data were then systematically categorized.

\section{Results and Findings}

The focus of this study is on the mediations in the students activities. In this regard, a detailed analysis has been done on the mediations from the peer resources, peer talk in particular in the activity of talking about living things. 


\subsection{Peer talk as mediation}

The following excerpts illustrate how peer talk functions as important mediations in the activity from different aspects: 1) peer prompting and waiting, 2) reciprocity of peer assistance, 3) active engagement and non-verbal expressions, 4) active involvement, self-correction and voice volume, 5) peer talk expansion and creativity, 6) coinage and private speech, 7) resistance and inquiry, 8) comments and social function of private speech, and 9)code-switching, turn-taking and thinking. Owing to the limited space where I cannot show all the analysis on the talk of the three pairs, only excerpts from the talk were extracted and shown here: Excerpts 1 to 2 are from the talk by Pair $\mathrm{W}$ and N; Excerpts 3 to 5 are from the talk by Group Y, C and X; and Excepts 6 to 9 are from the talk by Pair L and H.

\subsubsection{Introduction about the activity}

As this was an English immersion school, living science was one the content subjects for the immersion. In the science class, the teacher introduced to the students the living things and the non-living things, as well as the criteria of how to judge the living things and non-living things. After the science class, the teacher assigned the students to talk about living and non-living things in the evening self-study class (as this was a boarding school), which included 8 pictures (a butterfly, a robot, the Milky Way, an electronic dog, an orange, a flower, a rock and a sea creature) in the textbook on the theme of "growth and change". Four features were identified in living things for students to judge them by: 1) can it grow? 2) can it produce babies? 3) can it produce or get nutrition? 4) can it react to the stimulus around it?

\subsubsection{Peer prompting and waiting}

Excerpt 1: Talk about Butterfly by Pair W and N

$\mathrm{W}=$ Student $\mathrm{W}$

$\mathrm{N}=$ Student $\mathrm{N}$

1. N: This is a butterfly.

2. W: Is this a living things?

3. N: Yes.

4. W: Why.

5. N: Because (..)

6. W: It can (prompting in a low voice).

7. $\mathrm{N}:$ It (..)

8. W: can (prompting).

9. N: It can (0.6) fly.

In this excerpt, $\mathrm{W}$ and $\mathrm{N}$ are trying to reason why a butterfly is a living thing. In Line 5 , when $\mathrm{N}$ hesitates and pauses as he can not formulate and articulate the reason, W prompts in line 6 in a low voice with the two words needed "it can" in N's utterance. N picks up the prompted word "it" in line 7, but gets stuck there and still has difficulty to continue. W prompts again in line 8 with the word "can". $\mathrm{N}$ at this moment picks up the prompt and articulates the reason in line 9 with a pause of 6 seconds. From this episode, we can see that when $\mathrm{N}$ has some difficulty in the reasoning, W assists him with prompts patiently. When $\mathrm{N}$ comes to pick up the prompts in the end and gives the reason, $\mathrm{W}$ gives enough time to wait for $\mathrm{N}$ to talk. Peer prompting and waiting serve as mediation in their activity.

\subsubsection{Reciprocity of peer assistance}

Excerpt 2: Talk about robot by Pair W and N

$\mathrm{W}=$ Student $\mathrm{W}$

$\mathrm{N}=$ Student $\mathrm{N}$

1. W: What's this.

2. W: This is a (..) robot.

3. $\mathrm{N}: e r$ - is this the (..)

4. W: living thing (prompting in very low voice).

5. N: living thing?

6. W: No, it isn't.

7. N: Why.

8. W: Because (...) it no can - no can grown [grow]. 
9. $\quad \mathrm{N}$ : grow (correcting W)

In this excerpt, $\mathrm{W}$ and $\mathrm{N}$ are talking about whether the robot is a living thing or a non-living thing. In line 3 when $\mathrm{N}$ shows his difficulty with his stuttering filler "er-" and hesitation pause, W offers him prompts of "living thing" in line 4. In line $5, \mathrm{~N}$ picks up the prompts and completes his utterance with the question. In line 8 , when $\mathrm{W}$ has some erroneous pronunciation with "grow", $\mathrm{N}$ corrects her and provides her with the correct pronunciation in line 9. This excerpt shows that students show their multi-competency in their learning, and reciprocity emerges in the student peer assistance.

\subsubsection{Active engagement and non-verbal expressions}

Except 3: Talk about butterfly by Group Y, C and X

$\mathrm{Y}=$ Student $\mathrm{Y}$

$\mathrm{C}=$ Student $\mathrm{C}$

$\mathrm{X}=$ Student $\mathrm{X}$

1. $\mathrm{Y}$ : Is this a (..) living thing?

2. $X:$ No, it isn't. It's a living thing.

3. $\mathrm{Y}$ : (giggling, indicating he is wrong)

4. $\mathrm{X}:$ Yes, it is.

5. It's a living thing because it can fly.

6. It can- it can

7. $\mathrm{Y}$ : move (prompting)

8. $\mathrm{X}$ : move. It can reproduce babies.

9. C: Yes?

10. X: Yes.

11. Y \& $\mathrm{C}$ : (giggling)

In this excerpt, when $\mathrm{Y}$ asks $\mathrm{X}$ whether the butterfly is a living thing or not, $\mathrm{X}$ in line 2 gives a contradictory answer: first stating that "No, it isn' $t$ ", later stating that "it is a living thing." Y's giggling in line 3 makes X to confirm that the butterfly is a living thing in line 4 . Following that, $\mathrm{X}$ continues to give reasons for his statement in line 5 that "it can fly." In line 6 he repeats the phrase and tries to find out what he wants to express. Y prompts him in line 7 and X picks up the prompts in line 8 . Besides, he gives another reason that "it can reproduce babies." The conversation is dominated by $\mathrm{X}$ and $\mathrm{Y}$, which gives $\mathrm{C}$ very little chance to talk, however, $\mathrm{C}$ cleverly joins in the talk with a confirmation check "yes?" in line 10. This excerpt show us that in the peer talk, peer students' non-verbal expressions function as assistance for reflection, and that in the peer talk students are trying to find chances to participate in the talk to get actively engaged in the activity.

4.1.5 Active involvement, self-correction and voice volume

Excerpt 4: Talk about robot by Group Y, C and X

$\mathrm{Y}=$ Student $\mathrm{Y}$

$\mathrm{C}=$ Student $\mathrm{C}$

$\mathrm{X}=$ Student $\mathrm{X}$

1. $\mathrm{X}$ : Is this a living thing?

2. Y: No, it isn't.

3. $\mathrm{X}:$ en $(\ldots)$

4. C: why why why why (prompting in a low voice).

5. X: Why.

6. Y: Because it (..) it can (...) en (...) produce ba- he can (..) don't

7. $\mathrm{X}$ : reproduce (prompting)

8. Y: It don't produce baby:

9. $\mathrm{X}$ : Is this a living thing?

10. C: No, it is.

11. X: No, it ISN'T (correcting and prompting in a very low voice). 
12. C: No, it isn't.

13. X: Why?

14. C: Because

15. Y: it don't (..) er- introduce $e r$ - produce baby=

16. $\mathrm{X}:=$ and it can move

In this excerpt, the first part from line 1 to line 8 is mainly between $\mathrm{Y}$ and $\mathrm{X}$, however, $\mathrm{C}$ actively involves himself in the talk in line 4 prompting $X$ with "why" when he finds X stuttering with difficulty by the pause. X picks up in line 5 and $\mathrm{Y}$ explains the reason in line 6, where she shows difficulty in articulating the reason of "reproducing babies." $\mathrm{X}$ prompts her with the word, and Y picks up though confused with the words "produce" and "reproduce". In line 9, X projects the talk to $\mathrm{C}$ and asks him whether the robot is a living thing or not. $\mathrm{C}$, influenced by the $\mathrm{L} 1 \mathrm{in}$ mixing that answer of negative and positive, gives the erroneous answer to the question with "No, it is". X corrects him and has the stress laid on the word "isn't" in order to direct C's attention to the form. C immediately picks up in line 12. In the last 3 lines $\mathrm{C}, \mathrm{Y}$ and $\mathrm{X}$ are co-constructing the reasons. What is interesting here is that in line 15, $\mathrm{Y}$ corrects herself and finds the correct form to express in the talk. This excerpt shows us 1) that students are trying to involve the other party into the talk in the process, 2) that when peers correct their partners, they utilize voice volume to stress or emphasize and direct their attention consciously, and 3) that self-correction also occurs in the peer talk.

4.1.6 Talk expansion and creativity

Excerpt 5: Summary by Group Y, C and X

$\mathrm{Y}=$ Student $\mathrm{Y}$

$\mathrm{C}=$ Student $\mathrm{C}$

$\mathrm{X}=$ Student $\mathrm{X}$

1. $\mathrm{X}$ : Do you know their names?

2. Y: Yes. This is butterfly.

3. This is (..) robot

4. This is Milk Way

5. This is er

6. $\mathrm{X}$ : electronic dog (prompting in a very low voice).

7. Y: electronic dog

8. $e r$ - this is an orange.

9. This is water

10. $\mathrm{X}$ : water animals (prompting in a very low voice)

11. Y: water animals

12. This is er- this is

13. $\mathrm{X}$ : Rock (prompting in a very low voice).

14. Y: Rock.

15. This is a flower

In the excerpt, the students, not following the instructed pattern of asking and answering the questions, are conducting a free talk about the pictures. Through the expansion, they are using what they have learned in the situations they can find in the utterance "Do you know their names?", and even creatively using the language by creating a new phrase "water animal" for the "jellyfish" in line 10 and 11.

\subsubsection{Coinage and private speech}

Excerpt 6: Talk about orange by Pair $\mathrm{L}$ and $\mathrm{H}$

$\mathrm{L}=$ Student $\mathrm{L}$

$\mathrm{H}=$ Student $\mathrm{H}$

1. L: Is this an orange?

2. H: Yes, yes, it is.

3. L: Do you have 
4. $\quad$ bu dui $\{$ Not right\}

5. do you do: he:

6. H: ni shuo ta hui sheng zhang de \{You say it can grow\} (prompting in a low voice).

7. L: sheng zhang zen me shuo \{How to say "grow"? (asking for help)

8. H: sheng zhang? \{Grow\}?

9. Gray

10. L: Grow (correcting $\mathrm{H})$.

11. H: Grow

12. gu tou \{Bone.\} (coining the sound in Mandarin).

13. L: Can can he grow?

14. H: No: it isn't!

In this excerpt $\mathrm{L}$ and $\mathrm{H}$ are talking about whether orange is living thing or not. In line 4 and 5, private speech occurs when $\mathrm{L}$ tries to find out what she wants to express. H prompts in line 6 in $\mathrm{L} 1$ in a low voice, but $\mathrm{L}$ cannot pick up the prompt as she does not know how to say "grow". L asks $\mathrm{H}$ for help in line 7, and $\mathrm{H}$ prompts in line 8 with a wrong word "gray". However, though the prompted word is not correct, it reminds L of the correct word. In line $10 \mathrm{~L}$ finds the correct form and corrects $\mathrm{H}$ immediately. In line $11 \mathrm{H}$ repeats after $\mathrm{L}$ and tries in line 12 to internalize the word by building a connection between this new word and his previous knowledge of pronunciation: he coined the sound in mandarin as a strategy to learn the language.

4.1.8 Resistance and inquiry

Excerpt 7:Talk about Milky Way by Pair L and $\mathrm{H}$

$\mathrm{L}=$ Student $\mathrm{L}$

$\mathrm{H}=$ Student $\mathrm{H}$

1. $\mathrm{H}:$ Is // this a

2. $\mathrm{L}: / /$ What is this.

3. H: It's Milk Way.

4. L: Oh, it's beautiful.

5. $\mathrm{H}$ : Yes, it is.

6. L: Is this the living thing?

7. H: en:

8. L: No, it isn't (prompting in a very low voice).

9. H: I don't know.

10. L: en? (surprisingly)

11. Oh he is non-living thing.

12. H: Really?

13. L: Yes.

In this excerpt, $\mathrm{L}$ and $\mathrm{H}$ are trying to manipulate the free language use by giving comments to what they see and expressing their affect through such the utterance as "Oh, it's beautiful." In line 7 when $\mathrm{H}$ hesitates to give the answer, L prompts with an answer in a low voice. $\mathrm{H}$ refuses to pick it up as he is not sure about the answer, so he just answers "I don't know", which surprises L, as this is unusual. When L rephrases in line 11 the utterance with "non-living thing”, H gives his inquiry with "really?" in line 12 , which shows that he is not taking in what he is not sure of. Therefore, the students' free language use begins to emerge in their talk, and agency also shows in their talk.

4.1.9 Comments and social function of private speech

Excerpt 8: Talk about electronic dog by Pair L and $\mathrm{H}$

$\mathrm{L}=$ Student $\mathrm{L}$

$\mathrm{H}=$ Student $\mathrm{H}$

1. H: ji qi gou zen me shuo \{How to say "electronic dog"?\}? 
2. L: Is this the dog?

3. H: bu shi bu shi \{Not right, not right.\},

4. ji qi gou \{Electronic dog.\}

5. L: Is this the dog?

6. No, it is the

7. H: Chocolate

8. L: Chocolate (giggling)

9. It's the chocolate dog. It's cool

10. H: en, yes?

11. Really?

12. L: Yes, it is.

13. Is this the no- library (giggling) non- no no

14. shen me de \{What is it\}? (thinking cloud)

15. H: Non-living thing (prompting).

16. H: Yes.

In this excerpt, $\mathrm{H}$ seeks help from $\mathrm{L}$ when he cannot express "electronic dog" in line 1 . When $\mathrm{L}$ prompts him with only "the dog" in lines 2, 5 and 6, $\mathrm{H}$ emphasizes in L1 that it is "electronic dog". Then in line 7, $\mathrm{H}$ comes up with the word "Chocolate" which has some resemblance in pronunciation with "electronic", and they continue to co-constructs the following talk. L comments on Chocolate dog "cool" in line 9, but still there is uncertainty about the expression, which makes H inquire about it with "really?" In line 13, when L wants to say "non-living thing", she suddenly cannot express herself, and tries hard to find the word through private speech. Her private speech has some social function, which $\mathrm{H}$ hears it and prompts her with the phrase "non-living thing". In the peer talk, peers are seeking help from each other, and private speech occurs in their thinking process, which functions socially. Besides, students are using language freely to give comments to objects around them.

\subsubsection{Code-switching, turn-taking and thinking}

Excerpt 9: Expansion of talk by Pair $\mathrm{H}$ and $\mathrm{L}$

$\mathrm{H}=$ Student $\mathrm{H}$

$\mathrm{L}=$ Student $\mathrm{L}$

1. $\mathrm{L}$ : What what is it?

2. H: It's tree.

3. L: $e m$ ! The shu zhi is very long. \{This branch of the tree is very long.\}

4. H: Yes, it's very long.

5. L: Is this the living thing?

6. H: en, no, not living thing.

7. It's shi jia de \{It is artificial\}

8. L: It's non-living thing (prompting in a very low voice).

9. H: It's not living thing.

10. L: Oh?oh!

11. What time is it now?

12. H: It's seven thirty five.

13. L: Thank you.

14. What is it?

15. H: //It

16. L: // It's very

17. kong bu de zen me shuo \{How to say "terrible"? (asking for help)

18. H: zhi jie shuo zhong wen \{Speak in Chinese directly\} 
19. L: It is very kongbu \{It is very terrible.\}

20. H: Yes, me too.

21. L: Is this the living thing?

22. H: en, yes it's living thing.

23. L: ni jiang \{Your turn\} (in a very low voice).

24. hai you shen me living thing $a h$ ? \{What else is living thing?

25. $\mathrm{H}: / /$ tree

26. $\mathrm{L}: / /$ the tree

27. the $=$

28. $\mathrm{H}:=$ flower

29. L: the flower

30. H: grass

31. L: YES, grass and the: animal

32. H: em

33. L: and (..)

34. H: and ren \{human beings\}.

35. L: Yes.

In this excerpt, in line 3 and line 7, $\mathrm{L}$ and $\mathrm{H}$ use code-switching to express what they cannot express in English in order to maintain their talk. Similarly, in line 17, L seeks help to express "terrible" in English, and H tells her to code-switch in line 18. In line 19, L uses code-switching as $\mathrm{H}$ prompts. L prompts in line 8 in a low voice when she finds $\mathrm{H}$ has some difficulty in expressing himself, and $\mathrm{H}$ picks up the prompt immediately. The talk about the assignment appears to be over. However, $\mathrm{H}$ and $\mathrm{L}$ seize the chances to use English as much as possible, thus expand their talk. Then L uses "oh?oh!" as a transition in line 10 to signal the change of the theme, and she asks about the time in line 11, then they go on to talk about living things from line 14 to 24 . Students not only prompt the language expression to use, but also prompt turns for each other. In line $23, \mathrm{~L}$ reminds $\mathrm{H}$ of the turn he should take. What is exciting in this talk is that in the last part from line 24 to $35, \mathrm{~L}$ and $\mathrm{H}$ are co-constructing what else is living thing and expanding their talk in authentic thinking from concrete concepts such as "trees, flowers" to abstract concepts such as grass and animal. In the end, they connect humans to what they have learned about living things and non-living things, which shows that they are applying the abstract concepts into practice, connecting the remote to their intimate situation. In sum all these excerpts show that peer talk and peer assistance form the most important source of mediation in the student activity.

\subsection{Comparison among the three pairs/groups}

Aside from the mediation address above, the dynamics and interaction between the elements of the activity is to be explained through the comparison made among the three pairs, based on the components of the complex activity system: object, subject, mediation, rules, community, division of labor, outcome, peer relations in the peer talk and the strategies used respectively (see Table 1).

(Table 1 is here)

The students used a variety of strategies in their talk. Self-repetition and pauses were used to gain time for thinking and phrasing what they wanted to express. Peer correction and peer prompting scaffolded their talk where the low volume of their voice showed their efforts to minimize the asymmetry in their role relations. Code-switching was used when they could not express themselves in English. Self-repetition and self-correction were used in their talk together with peer correction, peer prompting, and giggling as a reminder. $\mathrm{X}$ and $\mathrm{Y}$ were dominating the talk without giving $\mathrm{C}$ any chance to participate in their talk. C listened to them carefully and skillfully used the word "yes" with the rising tone to initiate his participation in the activity. In $\mathrm{H}$ and L's talk, correction and peer prompting were also used in their talk to give each other scaffolding in the talk where the volume of voice was also lowered to show respect to their partners. H used coinage of the pronunciation for the new word to help him memorize the word. Code-switching occurred when $\mathrm{L}$ and $\mathrm{H}$ found they could not express themselves in English. Besides code-switching, tone-switching was used by L, for example she used "en" with the rising tone to show her surprise and disagreement, just as in L1; she used "hen" to show her irritation. Lastly, L used "oh?oh!" to mark as a sign poster for the ending of one picture and shifting to another picture.

\subsection{Categories of mediations}

Besides the mediations coming from the peer resources, peer talk in particular, other mediations are evidenced in this study, though no detailed analysis can be given here because of the limit of space. In this study, results show that in the 
activities the mediations include the following categories: teacher resources, peer resources, e realia, content, semiotic artifacts and other semiotic artifacts. Teacher resources include teacher's talk such as instruction, questioning, elaborating and prompting, teacher's tone and volume of voice; teacher's gestures; teacher's eye contact; teacher's presence and teacher's silence. Peer resources involve peer talk such as tutoring, questioning, elaborating, collaborating and prompting; peers' tone and volume of voice; peer play such as kidding, chanting and play with words; and peer gestures and actions. Semiotic artifacts contain texts, textbooks and the language used. Other semiotic artifacts comprise of worksheets, PPT, pictures and maps. Subject content plays a very important role in mediation as the present study involves an English immersion context. In addition, genre "is likely to affect the linguistic form" (Ellis, 2003, p.92), which enable students to accomplish their activities. The type of mediations can be summarized as follows (see table 2):

\section{(Table 2 is here)}

\subsection{Theoretical framework revisited: representations in this study}

The variety of mediations function as the most important part in the activity where Engestrom's model of activity system with its seven correlated components of object, mediation, rules, community, division of labor, object and outcome serves as the analytical framework. The subject refers to the peer students. When the students participate in the activities, the mediation refers to the psycholinguistic and other semiotic tools, as described above. Since the current study examines peer talk, the subjects in the activity system involved are peers either in pairs or in groups. Rules refer to the relations, norms, conventions and expectations in the community. Peer role relation is a very important aspect of the rules. Community in the current study refers to the pair or the group, the class and the school, as the study pertains to a boarding school and students stay at the school most of the time except during weekends. Classroom is the place where students have their class studies and do their self-studies in the evenings. Division of labor incorporates how the students divide their work in the activity. Object refers to the task-driven/related goals of achievements: the language, the content, and the culture behind the language. Outcome refers to participants' goal-directed achievements, the participants' discourse, and the affective satisfaction of collaborating with peers. Tasks are designed with the goal of eliciting the language in use (Ellis, 2003) and peer talk in the current study is selected as an indicator of the outcome. Peer talk, the indicator of outcome serves as a type of mediation at the same time. Figure 2 illustrates the representations which grounded from the data in the current study in Engestrom's (1999) framework.

\section{(Figure 2 is here)}

\subsection{Dynamic relations among the components of activity}

The relations among these components can be described as follows: Peer students, who are regulated by the rules in the community, divide their works, and deploy the devices of mediation to try to achieve their goals in the object. The goals refer to acquiring English language proficiency, mastering the content, and learning the culture embedded in the content subjects. Through the division of labors and through the process of their effort, their goals will be transformed into the outcome, which include the goal-directed achievement, or the process of the experience of achieving the goals, and the affective dissatisfaction or satisfaction of collaborating with peers, and the peer talk. As the nature of activity is situated, dynamic, dialectical and internally correlated, these arrows show the situatedness, the dynamical and relational nature of activity, which means that the change of one component may cause changes in the others.

\section{Discussion}

This study shows results consistent from the previous studies that students use language and physical tools such as realia as mediational tools in their peer learning processes. The study also expands the previous literature on mediation by discovering that in the student peer activities, mediation covers a wide range of areas from teacher's talk to peer talk, content, genre, semiotic artifacts and other semiotic tools, and that mediation includes task, teacher talk, peer talk, subject contents and other semiotic tools. Peer talk demonstrates multifaceted functions as mediation, which together with linguistic resources constitutes an important resource aside from teacher talk, where subject content serves as an important mediational tool in the activity and the content-based immersion programs, offering students opportunities of language use in meaningful interaction.

This study investigates the students' peer learning process through the lens of sociocultural theories, which offers insights into the immersion practice. It investigates mediational tools which students employed in their activities from an emic perspective, which provides a better understanding of the English immersion programs in China. It enriches practices of the classroom interaction among learners. The findings generated from this study of the English immersion programs present an in-depth analysis of the spoken English language learning process and offer valuable insights for pedagogy and teacher professional education.

Some implications of pedagogy and teacher education can be drawn. First, when designing tasks, teachers should be able to predict and have clear expectations of the dynamics of activities, as students conduct the activities based their own interpretation of the goals, the rules, the mediation and the setting, which results in different outcomes. Second, 
peer talk function as a most important mediation in students' English language learning, which, as an indicator, can reveal what is happening in the process of performing the task, and equip teachers to explain the reasons for the students' achievement. This can provide teachers with a clear and more complete picture of students' performance in the activities. Third, the fact that the change in one component within the activity system leads to different activities may give insights into the teacher education that the feasibility of variation of activities can be a way to satisfy the needs of different students.

The limitation of the study is that it investigated only the student spoken language, i.e., their peer talk in the activities. Further research can be done on the aspects of student written language discourse in their L2 proficiency development.

\section{Conclusion}

Mediations include the multiple resources such as teacher resources, peer resources, physical tools and semiotic tools. Peer talk functions as a most important source of mediation, where students demonstrate the deployment of communicative strategies such as prompts, and scaffolding help. Subject content serves as sources of mediation in the activity and the content-based immersion programs offer students opportunities of language use in meaningful interaction.

\section{References}

Cortazzi, M., \& Jin, L. X. (2001). Large classes in China: "Good" teachers and interaction. In D. A. Watkins \& J. B. Biggs (Eds.), Teaching the Chinese learner: Psychological and pedagogical perspectives. Hong Kong: Comarative Education Research Center, University of Hong Kong.

Engestrom, Y. (1987). Learning by expanding: An activity theoretical approach to development research. Helsinki: Orienta-Konsultit Oy.

Engestrom, Y., Miettinen, R., \& Punamaki, R.-L. (Eds.). (1999). Perspectives on activity theory. Cambridge: Cambrisge University Press.

Fang, J. M., Wang, J. Y., \& Siegel, L. (2001). Dangdai zhongguo shaoshuminzu shuangyu jiaoxue lilun yu shijian (Theory and practice of bilingual teaching of contemporary China's minorities). Xi'an: People's Education Press of Shaanxi Province.

Francis, N., \& Reyhner, J. A. (2002). Language and literacy teaching for indigenous education: A bilingual approach. Clevedon: Multilingual Matters.

Hu, G. W. (2002a). Potential cultural resistance to pedagogical imports: The case of communicative language teaching in China. Language, Culture and Curriculum, 15(2), 93-105.

Hu, G. W. (2002b). Recent important developments in secondary English-language teaching in the People's Republic of China. Language, Culture and Curriculum, 15(1), 30-49.

Pei, M. (1998). The teachers: The key role in English immersion program. Shaanxi Normal University Journal(Supplementary issue), 27-31.

Qiang, H. Y. (2000). Jianada di'eryuyan jinrushi jiaoxue chuangju jiqi zai woguo de changshi (Canadian second language immersion and experiment in China: Research on early cultivating the bilingual). Preschool Education Review, $5,25-28$.

Qiang, H. Y., \& Zhao, L. (2000). Jianada di'eryuyan jinrushi jiaoxue chuangju jiqi zai woguo de jiejian (Canadian second language immersion and application in China. Comparative Education Review, 4, 38-41.

Qiang, H. Y., \& Zhao, L. (Eds.). (2001). Second language immersion. Xi'an: Xi'an Jiaotong University Press.

Reyhner, J. (1998). What's immersion education? Retrieved in July 2007, from http://www.uatuahine.hawaii.edu/hana/si98/jar/vocab.html.

Tsui, A. B. M., \& Law, D. Y. K. (2007). Learning as boundary crossing in school university partnership. Teaching and Teacher Education, 23, 1289-1301.

Yu, L. M. (2001). Communicative language teaching in China: Progress and resistance. TESOL Quarterly, 35, 194-198.

Zhang, X. Z., \& Pei, M. (2005). Problems in primary school English immersion curriculum and experimental instruction. Elementary English Teaching Journal, 5(7), 9-11.

Zhao, L., \& Qiang, H. Y. (2002). Ertong zaoqi di'er yuyan jinrushi jiaoxue yu kecheng jiangou yanjiu (Research on children's second language immersion and curriculum construction). Preschool Education Review, 4, 30-33.

Zou, Y. Y. (1998). English training for professionals in China: Introducing a successful EFL training programme. System, 26(2), 235-248. 


\section{Acknowledgement}

I owe my progress in HKU to my supervisors Prof. Andrews, Dr. Luk, Prof. Davison. Special thanks are given to Dr. Clarke, and Prof. Tsui as my committee members. Thanks are also given to Prof. Qiang of the CCUEI, Ms Gao, Ms Xiu and $\mathrm{Mr}$. Yu of the school for their support and cooperation. This study could not have been carried out without their guidance and support.

\section{Appendix I: Conventions of transcription}

\section{Symbols}

$\mathrm{Ss}$

[]

(XX)

.

(..)

(...)

$(0.6 / 7 / 8 \ldots)$$$
\text { number }
$$$$
\text { , }
$$$$
\text { ? }
$$$$
\text { ! }
$$$$
\text { : }
$$$$
-
$$

\section{CAPS}

$=$

//

$<$ xxx $>$

following ones

\section{A-B-C-D \\ $\{\ldots\}$}

( )

Italics

Bold

\{\}

$$
><
$$

Meaning

\section{Students}

Researcher's comments

$$
\text { Uncertain hearing }
$$

Indecipherable utterances

Falling intonation followed by noticeable pause (as at the end of the declarative sentence)

\section{Short pause}

Medium pause of up to 5 seconds

For wait time longer than $5 \mathrm{sec}$, the pause will be represented by figures showing the .Wait time longer than one minutes will become (1.0) and so on

Continuing intonation

Rising intonation, usually a question

High falling pitch showing exclamations

Lengthened syllable (usually attached to vowels); extra colon indicates longer elongation

Self-halting, or abrupt cutoff

Emphatic and strongly stressed utterances

Contiguous utterances or latching

\section{Overlapping}

Utterances made with a greater voice volume compared with that of the preceding and Sounding out the letter names of a word untranscribed section of the excerpt

Explanation of gestures or tone changes like smiling or laughing and so on Putonghua (code-switching)

Cantonese (code-switching)

Translation of the code-switching

Speech in a faster pace.

text provided (by the teacher or in the textbooks or other materials)

(The last five items are s added by me) 
Table 1. Comparison among the three pairs

\begin{tabular}{|c|c|c|c|}
\hline Components & Pair $\mathrm{W}$ and $\mathrm{N}$ & Group $\mathrm{Y}, \mathrm{C}$ and $\mathrm{X}$ & Pair $\mathrm{H}$ and $\mathrm{L}$ \\
\hline Object & $\begin{array}{l}\text { To talk about } 8 \text { pictures and } \\
\text { decide whether they are } \\
\text { living things or not }\end{array}$ & $\begin{array}{l}\text { To talk about } 8 \text { pictures and } \\
\text { decide whether they are } \\
\text { living things or not }\end{array}$ & $\begin{array}{l}\text { To talk about } 8 \text { pictures and decide } \\
\text { whether they are living things or } \\
\text { not }\end{array}$ \\
\hline subject & $\mathrm{W}$ and $\mathrm{N}$ & Group Y, C and X & $\mathrm{H}$ and $\mathrm{L}$ \\
\hline mediation & $\begin{array}{l}\text { the pictures, the vocabulary } \\
\text { of the content subject, peer } \\
\text { prompts, the volume of their } \\
\text { voice, and } \\
\text { (code-switching) }\end{array}$ & $\begin{array}{l}\text { the pictures, the vocabulary } \\
\text { of the content subject, peer } \\
\text { correction, peer prompts, and } \\
\text { the volume of their voice }\end{array}$ & $\begin{array}{l}\text { the pictures, the vocabulary of the } \\
\text { content subject, peer correction, } \\
\text { peer prompts, the volume of their } \\
\text { voice and L1 (code/tone-switching) }\end{array}$ \\
\hline rules & $\begin{array}{l}\text { Completion of the task, } \\
\text { taking turn to ask and answer } \\
\text { questions }\end{array}$ & $\begin{array}{l}\text { Completion of the task, } \\
\text { taking turn to ask and answer } \\
\text { questions }\end{array}$ & $\begin{array}{l}\text { Completion of the task, taking turn } \\
\text { to ask and answer questions }\end{array}$ \\
\hline community & Work as a pair in the class & Work as a pair in the class & Work as a pair \\
\hline Division of labor & $\begin{array}{l}\mathrm{W} \text { asked, } \mathrm{N} \text { answered, } \\
\text { regularly they switched their } \\
\text { roles. }\end{array}$ & $\begin{array}{l}\mathrm{Y} \text { and } \mathrm{X} \text { seemed dominant } \\
\text { the talk, } \mathrm{C} \text { tried to participate }\end{array}$ & $\begin{array}{l}\mathrm{H} \text { initiated, } \mathrm{L} \text { answered, then } \mathrm{L} \\
\text { asked questions all the way }\end{array}$ \\
\hline outcome & $\begin{array}{l}\text { Completed talking about the } \\
8 \text { pictures, following the } \\
\text { same pattern. A little } \\
\text { code-switching, satisfied }\end{array}$ & $\begin{array}{l}\text { Completed talking about the } \\
8 \text { pictures, naming the things } \\
\text { in the pictures, no } \\
\text { code-switching, happy }\end{array}$ & $\begin{array}{l}\text { Completed talking about the } 6 \\
\text { pictures, expanded their talk to } \\
\text { categorize things around them, } \\
\text { satisfied though disputable }\end{array}$ \\
\hline $\begin{array}{l}\text { Role relations in the peer } \\
\text { talk }\end{array}$ & collaborative & $\begin{array}{l}\text { Between collaborative and } \\
\text { dominant/ passive }\end{array}$ & $\begin{array}{l}\text { Between collaborative and } \\
\text { dominant/ dominant }\end{array}$ \\
\hline Strategies used & $\begin{array}{l}\text { Self-repetition, pauses, } \\
\text { peer-prompting, } \\
\text { peer-correction, the volume } \\
\text { of their voice, } \\
\text { code-switching }\end{array}$ & $\begin{array}{l}\text { self-repetition, } \\
\text { self-correction, giggling, } \\
\text { peer correction, peer } \\
\text { prompting, the volume of } \\
\text { their voice, C's use of "yes?" }\end{array}$ & $\begin{array}{l}\text { Peer correction, peer prompting, the } \\
\text { volume of their voice, L's use of } \\
\text { "oh?oh!", the coinage of the } \\
\text { pronunciation, code/tone- } \\
\text { switching, }\end{array}$ \\
\hline
\end{tabular}

Table 2. Types of mediation

\begin{tabular}{ll}
\hline Type of mediation & \multicolumn{1}{c}{ Examples of mediation } \\
\hline Teacher resources & $\begin{array}{l}\text { teacher talk (instruction, questioning, elaborating, and prompting) } \\
\text { teacher's gestures, teacher's eye contact, } \\
\text { teacher's tone and volume of voice, teacher's silence, teacher's presence }\end{array}$ \\
\hline Peer resources & $\begin{array}{l}\text { peer talk (tutoring, questioning, elaborating, collaborating and prompting), } \\
\text { peer's gestures and actions, } \\
\text { peer's tone and volume of voice, } \\
\text { peer play (kidding, chanting, play with words) }\end{array}$ \\
\hline Realias & flowers, clothes, clock, etc \\
\hline Semiotic artifacts & languages, texts, textbooks, \\
\hline Other semiotic artifacts & PPT, pictures, maps, worksheets, etc \\
\hline Content, & subject contents (e.g. traffic rules in social science, living things in science) \\
\hline Genre & $\begin{array}{l}\text { The discourse mode students use to accomplish the task such as 'object description”, } \\
\text { narrative, expository, argumentational. }\end{array}$ \\
\hline
\end{tabular}


AT

\section{Mediated tools}

Subject

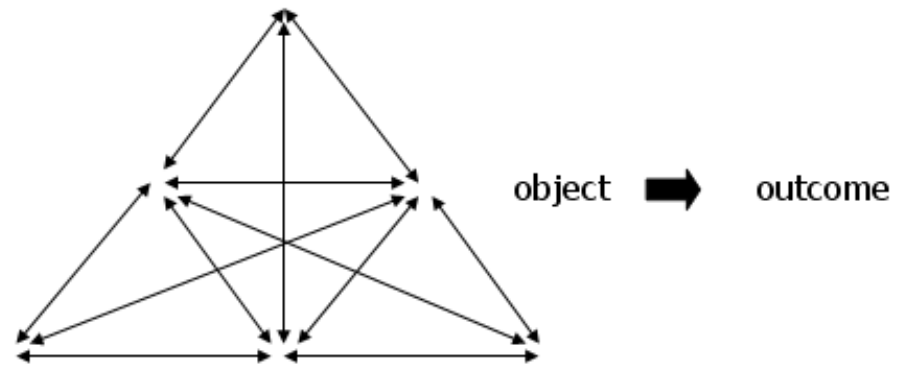

rules

community

Division of labor

Figure 1. The Complex Activity System (Engestrom et al., 1999, p. 31)

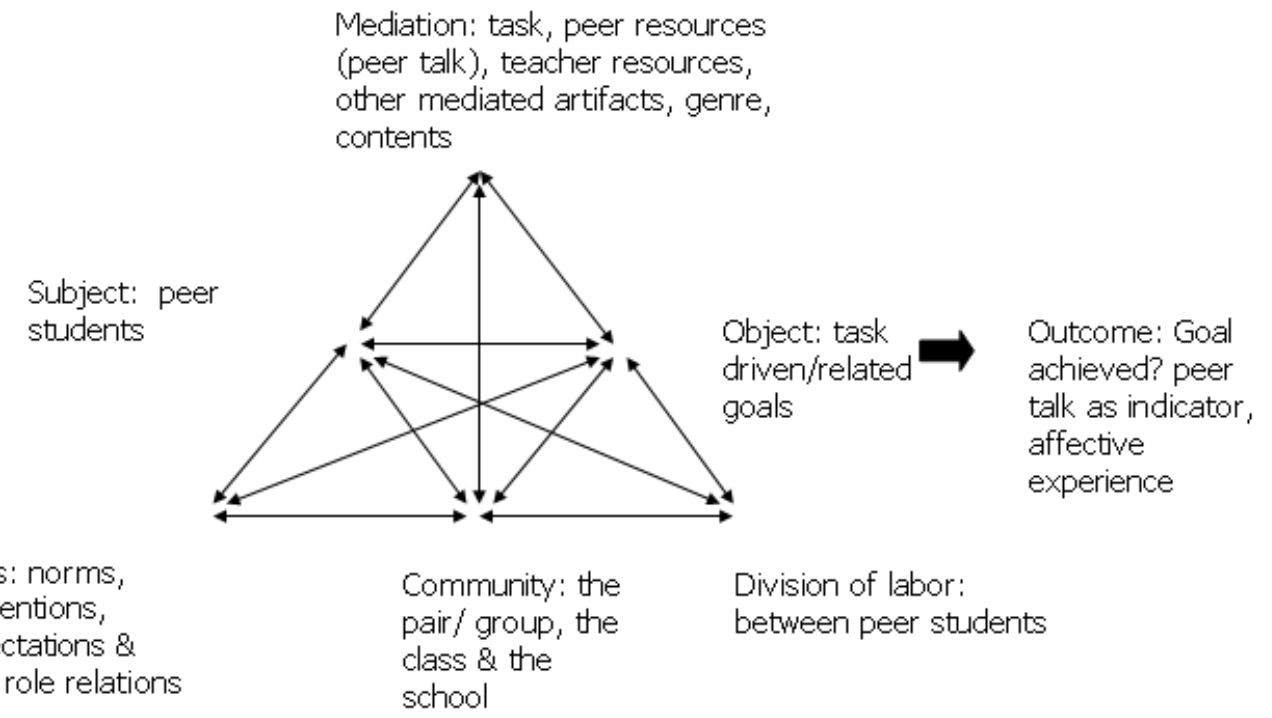

Figure 2. The current study in Engostom's framework (Based on Engestrom, Mittinen and Panamaki, 1999, p.31) 